\title{
Research on Transitional Education of Freshmen Majoring in Software Engineering
}

\author{
Yan Changshun, Shao Yong* \\ Faculty of Information Technology, Beijing University of Technology, Beijing, China \\ Email address: \\ yuewuxing@bjut.edu.cn (Yan Changshun), shaoyong@bjut.edu.cn (Shao Yong) \\ ${ }^{*}$ Corresponding author
}

To cite this article:

Yan Changshun, Shao Yong. Research on Transitional Education of Freshmen Majoring in Software Engineering. Higher Education Research. Vol. 6, No. 5, 2021, pp. 109-113. doi: 10.11648/j.her.20210605.12

Received: August 23, 2021; Accepted: September 13, 2021; Published: September 14, 2021

\begin{abstract}
In China, entering higher education is an ideal for parents and students to study hard for 12 years. They have made a lot of efforts in time and economy. However, because the goal of students in high school tends to be single, academic achievement has become the capital for students to be proud at this stage. However, after arriving at the University, due to the lack of direction and guidance in the goal, their choice is often poor in purpose, stability and persistence. Most students are addicted to the Internet, love and various student community activities. So, as university educators, how to make them complete the transition from high school to university life will be an important topic. From the perspectives of students, teachers and schools, this paper will analyze and explore the problems existing in the Transitional Education of freshmen majoring in software engineering in Beijing University of technology. At the same time, from the aspects of College Students' physical and mental health, ideological and cultural education, the guidance of the engineering education objectives of this major, a variety of measures to optimize the curriculum system Teachers' self-improvement and the overall improvement of the school give the corresponding specific countermeasures. I hope it can give some enlightenment to relevant educators.
\end{abstract}

Keywords: Higher Education, Freshmen, Transition Period

\section{Introduction}

The connection between high school education and higher education is easy to be ignored. Many parents believe that their children can be free when they go to college, and students can do their own things freely. In fact, this is a misunderstanding of concept. University is a more important starting point of life. It is very important to do a good job in the connection between students' psychology and thought.

With the support of national policies and through its unremitting efforts, the school of software of Beijing University of technology has made certain achievements in enrollment, talent training and the combination of industry, University and research. However, the rapid and diversified development of society objectively requires software colleges to constantly adjust themselves in time. Recently, we found that the training method for freshmen is too single and there are many risks. Through research, we found that freshmen live an ascetic life in high school, while university is a new starting point of life. It is a place for people to put on the wings of their dreams and fly [1]. Many people can fly high here, but many people fold their wings here [2]. There are many reasons, so we need to analyze it comprehensively. We have grasped this contradiction and carried out a series of reform and exploration in the way of talent training, the construction of curriculum system and personnel management.

\section{Analysis of the Problems in the New Transitional Period}

\subsection{Psychological Problems of Freshmen}

There is a single wooden bridge between high school and university. Does crossing this single wooden bridge mean that students are on a smooth road. In fact, the interests of students in high school tend to be single because of the simplification of goals. At this stage, academic achievement has become the only capital for students to be proud [3]. The praise of teachers, parents and classmates has become the source of their struggle. However, after arriving at the 
University, the achievement is not only the only indicator to measure whether a student is excellent or not, and the teacher is no longer around the students all the time [4]. For a moment, the students have a feeling of suddenly entering a vacuum [5]. His inner vision of the university has become less beautiful. Because of the lack of direction and guidance in their goals, they are just choosing different life paths at will, such as choosing to join some interested communities; Choose the fight of network virtual world; Choose the opposite sex to fall in love and so on [6]. There is nothing wrong with the diversification of College Students' goals and the enrichment of choices, but the minds of these young or nearly adult children are not really mature. Their choices are often poor in purpose, stability and persistence, and are very easy to cause various psychological problems.

\subsection{Problems in the Work of Freshmen Teachers}

Most of the class posts and counselors of freshmen are young teachers [7]. They are energetic, self-motivated and easy to integrate with students [8]. At the same time, new teachers also lack experience, which also brings obstacles to their teaching and education. I am a new teacher who has just entered the University [9]. Recalling the student life not long ago, many new teachers also experienced various psychological ups and downs at that time [10]. At that time, they were embarrassed to talk to others and had to bear and solve it alone. Sometimes they had the idea of giving up their studies and wandering around the world. Today, they have become freshmen. Although they can understand some of their problems and adjust them to a certain extent, they still feel that they can't start when facing new problems. They always hope to have a guiding light to help me adapt to the post of college teachers as soon as possible [11].

\subsection{Problems of Freshmen's School Management}

School is a big environment for freshmen to study and work [12]. It is like a piece of soil. Whoever can provide enough nutrition can breed rich fruits. At present, the school management system of college students is often strict, but the implementation is limited. On the one hand, the school requires students to actively participate in classroom learning and has issued corresponding punishment measures [13]. On the other hand, because college students are adults, they have their own freedom of choice [14]. Even if they do not attend classes or participate in various activities organized by the school, they are more subject to rigid punishment and lack of flexible management [15]; For the failure, cheating and even dropping out of college, many children are only restricted by the system, lacking a communication platform [16]; In fact, there is no problem with the intelligence of children who can enter the University. The problem is that China's education is inverted. Before the University, it is an ascetic life. When the university is enjoying life, the students' learning enthusiasm and initiative are poor. How to scientifically and reasonably mobilize the students' learning enthusiasm is the responsibility that the school should shoulder. It is difficult to fundamentally solve these problems by simply relying on some rigid punishment means.

\section{Coping Strategies in the New Transition Period}

The problem of Freshmen's transition period is reflected in different schools to varying degrees. We must help them solve it as soon as possible. The following are some effective countermeasures summarized by the school of software of Beijing University of Technology:

\subsection{Pay Attention to the Physical and Mental Health of College Students}

We all say that the current generation are little emperors. They are basically only children and are taken care of at home. It seems that they lack nothing. However, due to the excessive doting of parents, schools pay too much attention to the enrollment rate, and their physical and psychological quality are poor. Before going to college, some schools shortened the time of physical exercise in order to increase the enrollment rate. Many fierce games, such as basketball and football, let students play by themselves. They are afraid of students' injury or conflict, which greatly weakens the effect of students' exercise. In the face of such a reality, universities should actively organize various community activities, let students organize and plan a series of activities by themselves through interest, and improve their own organization and management ability while exercising their body; College students are adults, but many children are not mature enough. There are obstacles in accommodation, study and making friends. Therefore, the school should further strengthen the publicity and treatment activities of psychological counseling, so that college students can realize that psychological problems are encountered by everyone and should be treated normally, Using scientific methods can help themselves out of the misunderstanding as soon as possible, eliminate college students' aversion to psychological counseling, help freshmen adapt to campus life as soon as possible, and establish a correct view of University.

\subsection{Strengthen Ideological and Cultural Education}

The integration of contemporary college students' thoughts and culture between China and the west is a good thing, but now many times they absorb more from the outside and less from themselves. The essence of our national thought and culture is gradually missing. We should make students realize that from the war of resistance against Japan to the war of liberation, from the waste waiting to flourish when the founding of the people's Republic of China to the prosperity now. In the more than 100 years since the founding of the party, we have witnessed that the party has led the Chinese people to overcome various difficulties again and again and achieved one great miracle after another, such as growing from a spark to the only party in power; Such as defeating planes and tanks with millet and rifles; For example, two bombs and one 
satellite have been developed under the condition of active lack of resources; For example, we have achieved a well-off society in an all-round way in the new century. One miracle after another shocked the world, but our party has never stopped moving forward. Although the road ahead is difficult, let the students firmly believe that as long as they follow the party, they will reach the end of victory. At the same time, China is a civilized country with a long culture of 5000 years. In the early stage of reform and opening up, we vigorously developed material civilization while ignoring the synchronous development of spiritual civilization. We discovered this problem in time and strengthened the construction of spiritual civilization while continuing to develop material civilization with high quality. We should let students absorb the essence of 5000 years of culture and foreign culture, and strengthen the spiritual guidance of thought in combination with the specific national conditions of the new era. Material is mainly to strengthen your physique, and spirit is the fundamental for you to overcome difficulties, persevere and forge ahead.

\subsection{Strengthen the Guidance of Engineering Education Objectives of the Specialty}

Conduct professional cognitive education through the website of the Ministry of information science, freshmen entrance education, scientific and technological activities and other diversified ways to make students understand the training objectives and graduation requirements of their major. Constantly strengthen the understanding of training objectives and graduation requirements in the training links such as freshman seminar, engineering master Forum Report, curriculum design, work practice, graduation design, extracurricular practice and competition activities. At present, according to the guiding opinions of Beijing University of technology on formulating the 2020 version of talent training program, the software college closely focuses on the needs of the country and the economic construction and social development of Beijing, Tianjin and Hebei for the training of high-quality innovative computing talents, Based on the national standard for teaching quality of undergraduate majors in Colleges and universities and the certification standard for engineering education specialty issued by the Ministry of education, adhere to the principle of "building morality, cultivating people, laying a solid foundation, highlighting practice, encouraging innovation, promoting cross cutting and facing the world", and implement the University's "standing in Beijing, integrating into Beijing and radiating the whole country The school running orientation of "facing the world" and the school running requirements of building an "internationally famous, distinctive and high-level" Research University, so as to build a first-class software engineering specialty. The training objectives of the latest 2020 edition are: to cultivate students who adapt to the national and Beijing economic construction and social development, have good morality and cultivation, abide by laws and regulations, have social and environmental awareness, master the basic theory, relevant technology and practical methods of software engineering, and have the ability of scientific thinking including computing thinking and design computing solutions The ability to realize the system based on computing principles, the ability to design and implement large and medium-sized software systems, manage and improve software process models, organizational leadership and project management, and the international high-quality software professionals who have the spirit of innovation, team spirit, professionalism and pioneering consciousness to meet the development requirements of the times. Graduates of this major are suitable for application software development, software project management, information system operation and maintenance and information management in various enterprises, institutions and state organs. Five years after graduation, graduates can become engineers, or become heads of enterprise software R \& D teams, project managers and innovative enterprises.

Students of this major mainly study the basic knowledge and basic theory of software engineering, master the basic theory and basic knowledge of software system analysis, design, development and testing, and receive basic training in specialized knowledge and technology in software technology and application, embedded software and system, big data and service engineering, etc, Have the ability to engage in scientific research, technology development and service management in software engineering and related fields. After four years of study, students majoring in software engineering should basically master the following abilities.

1. Establish socialist core values and correct world outlook and outlook on life, be patriotic and dedicated, and have good moral cultivation and sense of social responsibility; Pay attention to humanistic quality, establish the concept of rule of law and civic awareness, abide by discipline and law, and academic ethics; Master certain labor skills, advocate labor and develop good habits of labor.

2. Master the knowledge of mathematics, natural science, economics and management required for the work of this major, and be able to use the basic and professional knowledge of mathematics, natural science, engineering to solve complex engineering problems in the professional field of software engineering.

3. Be able to apply the basic principles of mathematics, natural science and Engineering Science, identify and express, and analyze complex engineering problems in the professional field of software engineering through literature research, so as to obtain effective conclusions.

4. Systematically master professional basic theoretical knowledge and professional knowledge, experience systematic professional practice, understand the basic concepts, knowledge structure and typical methods of computing discipline, and establish core professional consciousness such as digitization, algorithm, modularization and hierarchy. Be able to design solutions to complex engineering problems in the professional field of software engineering, design and implement software systems that meet specific needs, 
and consider social, health, safety, legal, cultural, environmental and other factors.

5. Master the basic thinking methods and research methods of computing discipline, and have good scientific literacy and strong engineering consciousness or research and exploration consciousness. Be able to study complex engineering problems in the professional field of software engineering based on scientific principles and scientific methods, including designing experiments, analyzing and interpreting data, and obtaining reasonable and effective conclusions through information synthesis.

6. Be able to develop, select and use appropriate technologies and resources for complex engineering problems in the field of software engineering, make full use of modern engineering tools and information technology tools, simulate and predict complex engineering problems, and understand their limitations.

7. Be able to conduct reasonable analysis based on relevant background knowledge in the field of software engineering, evaluate the impact of practice in the field of software engineering and solutions to complex engineering problems on society, health, safety, law and culture, and understand the responsibilities to be undertaken.

8. Be able to understand and evaluate the impact of engineering practice on environmental and social sustainable development for complex engineering problems in the professional field of software engineering.

9. Understand the important laws, regulations, guidelines and policies of the profession and industry related to this major, have humanistic and social science literacy and sense of social responsibility, and be able to understand and abide by engineering professional ethics and norms and fulfill responsibilities in the practice of software engineering.

10. Have the ability of organization and management, expression, independent work, interpersonal communication and team cooperation, and be able to play the role of individual, team member and leader in a team with a multidisciplinary background.

11. Be able to effectively communicate with industry peers and the public on complex engineering problems of software engineering, including writing reports and design manuscripts, making statements, clearly expressing or responding to instructions. And have a certain international vision and be able to communicate and exchange in a cross-cultural context.

12. Be able to understand and master the principles of software engineering management and economic decision-making methods, and can be applied in a multidisciplinary environment.

13. Have the awareness of independent learning and lifelong learning, be able to use modern information technology to obtain relevant information, new technology and new knowledge, and have the ability to continuously learn and adapt to development.

14. Master the general knowledge and basic methods of sports, form good physical exercise and health habits, and meet the qualified standard of physical exercise for college students stipulated by the state.

15. Understand the development status and trend of software engineering discipline, have innovation consciousness, and have the preliminary ability of technological innovation and product innovation.

\subsection{Various Measures to Optimize the Curriculum System}

Firstly, a questionnaire is adopted. The needs are obtained by issuing questionnaires to students, graduates and employers, and the curriculum system is preliminarily designed according to the scientific analysis of the survey results.

Secondly, it adopts the way of discussion. The college often convenes experts from the school and external software engineering to discuss the training and curriculum, and clarify the target orientation of student training, curriculum system and supporting teachers from the actual needs of students.

Thirdly, the content system cultivated at the beginning of the previous course cannot be modified, but at present, we have adopted a flexible way of review and modification. Because we found that there was a certain deviation in students' focus on knowledge in the specific teaching process, we communicated with teachers in time to change the focus of knowledge points, which well met the actual needs of students.

Finally, we must abandon the previous thought of focusing on me and think from multiple perspectives with students with different ideas, so as to make our curriculum system more perfect and students learn more.

\subsection{Teachers' Self-improvement}

Teachers should strive to improve themselves, get familiar with and gradually master various educational skills as soon as possible. My personal experience is mainly reflected in the following aspects: first, people should maintain a good mental state in order to complete the task well. Poor mental state will also have a great impact on work motivation, work standards and work results. Maintaining a good mental state is not only the basis for doing work, the premise for completing tasks, but also a comprehensive embodiment of improving combat effectiveness. Although there are pressures and setbacks in work, we should not be intimidated by the current difficulties, but on the basis of constantly improving our own ability, cheer up, actively think of ways and ideas to complete various tasks; Secondly, we should dare to self-criticism and accept criticism in order to improve our work style. If a person is not good at criticizing himself and does not dare to accept criticism, he cannot grasp himself well and improve his work style. Only those who often analyze themselves and are willing to accept criticism can know themselves well, find the gap in their work and see the dangers in their progress. Only when we fully understand ourselves, find the gap and constantly correct the course of life, can we improve 
ourselves and correct our work style.

\subsection{Comprehensive Improvement of the School}

Finally, the school should make unremitting efforts from all aspects. Improving the quality of higher education is the core of building a powerful country in higher education, and the construction of teachers is the most key link in building a powerful country in higher education. Young teachers are the hope of the future of the school, the new force of the construction of "quality project", and the key to improve the quality of education and teaching at present and in the future. The school should make great efforts to do a good job in the training of young teachers and the professional development of teaching. Efforts should be made to enable young teachers to establish professional ideals and strengthen the cultivation of teachers' ethics; Study education and teaching theory hard and practice basic teaching skills hard; Establish team consciousness and improve communication and cooperation ability; Develop good thinking habits of reflective teaching; Consciously carry out education and teaching research and correctly handle the relationship between teaching and scientific research; Scientifically plan your career and grow into qualified college teachers as soon as possible. At the same time, the school should also invest a lot of financial, material and human resources in the construction of campus environment and campus culture, so as to truly create a platform and soil for students' quality training.

\section{Conclusion}

If the problems of freshmen are carefully observed and studied, there are still certain rules to follow. Although different students have different problems, they all have certain solutions and methods. As long as they make good use of them, they can be solved satisfactorily. As educators, only by learning and learning again and constantly improving ourselves can we help us better communicate with them, find their problems as soon as possible and help them find ways to solve them as soon as possible. With a lighthouse, ships will no longer lose their course; With the tireless efforts of educators, I also hope that college students can find their own way of life.

\section{Acknowledgements}

My thesis would like to thank the course construction project (040000513125) of School of software, Faculty of information Technology, Beijing University of technology for its financial support. In the process of our research, the required experimental and testing environment is also provided by the college. At the same time, I would also like to thank the authors of references and related researchers. Their research has given me important reference and help, and provided a good reference for the completion of my thesis.

\section{References}

[1] Guyu Li, On College Students' psychological problems from the perspective of ERG theory. Xuexiao Dangjian Yu Sixiang Jiaoyu, Vol 3, 2021, pp. 84-85, 89.

[2] Wen Yan, Research on psychological problems of college students after 00. Western China Quality Education, Vol 7, 2020, pp. 100-102.

[3] Cuiting Ma, Research on psychological problems of College Students. Journal of Higher Education, Vol 23, 2020, pp. $50-52$.

[4] Xiaoyin Lian, Research on the prevention and control of College Students' psychological problems. Encyclopedia Form, Vol 8, 2020, pp. 788.

[5] Rong Sun, Characteristics of College Students' psychological problems and mental health education. Charming China, Vol 48, 2020, pp. 259.

[6] Huanhuan Li, Analysis and Countermeasures of psychological problems of college students from single parent families. Modern Vocational Education, Vol 40, 2020, pp. 64-65.

[7] Jiling Song, Problems and Countermeasures in the ideological work of young teachers in Colleges and Universities. Jiangsu Higher Education, Vol 1, 2016, pp. 85-87.

[8] Yiying Wang, Research on the working hours of College Teachers. Journal of Juamjusi Education Institute, Vol 5, 2021, pp. 44-45.

[9] Meijuan Sun, Challenges and Countermeasures for College Teachers under the background of internationalization of Higher Education. Teacher, Vol 29, 2020, pp. 103-104.

[10] Yiming Chen, Ran Zhou, Qiuling Feng, Discussion on the problems, causes and Countermeasures of normal students' head teachers' working skills. Guangxi Education, Vol 9, 2020, pp. 106-108.

[11] Yawen Qiao, Abing Hou, Review and Prospect of the Research in Occupational Adaptation of New Teachers' in Colleges and Universities. Continue Education Research, Vol 2, 2021, pp. 95-101.

[12] Jiaqi liu, The purpose, value and method of cultural management in Colleges and Universities. Popular Standardization, Vol 9, 2021, pp. 164-166.

[13] Qianqian Shen, Problems and Solutions of the Internal Administration System Reform in Colleges and Universities. Journal of Tianjin Manager College, Vol 4, 2020, pp. 50-52.

[14] Xiaorong $\mathrm{Hu}$, Problems and Countermeasures in the construction of teaching management team in Colleges and Universities. Charming China, Vol 11, 2020, pp. 155-156.

[15] Qian Zhao, Zheng Pang, Ting Lu, Problems and Countermeasures of school management in multi campus colleges and Universities. Liaoning Economy, Vol 8, 2020, pp. 94-96.

[16] Fucheng Liu, Xuemei Gou, Research on Classified Management of Colleges and Universities in Jilin Province.

[17] Journal of Educational Institute of Jilin Province, Vol 8, 2020, pp. 139-145. 